\title{
The Impact of Local Funding on the Technical Efficiency of Oklahoma Schools
}

\author{
Lee C. Adkins* \\ Oklahoma State University \\ Ronald L. Moomaw ${ }^{\dagger}$ \\ Oklahoma State University and \\ Center for European Integration Studies, University of Bonn
}

April 26, 2003

\begin{abstract}
The parameters of a stochastic production frontier and the determinants of X-inefficiency are estimated simultaneously using a maximum likelihood estimator proposed by Battese and Coelli (1995). The purpose is to test the effect of local control and funding on public school X-inefficiency.

JEL Code: I22

Key Words: Technical efficiency, stochastic production frontier, school funding sources
\end{abstract}

*Department of Economics, Oklahoma State University, Stillwater, OK 74078 (email: ladkins@okstate.edu).

${ }^{\dagger}$ Department of Economics, Oklahoma State University, Stillwater, OK 74078 (e-mail: rmoomaw@okstate.edu). 


\section{Introduction}

Local funding of public schools is under attack because of its perceived inequities. Switching from local to state funding, however, may adversely affect public school performance. Hoxby (1999), for instance, argues that local funding and control of schools, through a Tiebout mechanism, can generate lower costs and greater attainment than a system with state funding and control. Here, we estimate a stochastic production frontier and provide direct evidence that intrastate variations in local support affect school system X-inefficiency, as she predicts.

In our view, local control produces a more efficient school system because it locates decision making with the people who have the greatest stakes in the school system. It provides greater authority to parents and students acting through parents, so that their expectations can promote better school performance. Local property tax payers also have incentives to promote efficient schools because the value of the better schools gets capitalized into property values. Finally, school administrators and teachers also benefit from increased local property values Hoxby (1999).

The evidence provided below is based on data from the 1990 census and the National Center for Education Statistics. An educational production function is estimated using an estimator proposed by Battese and Coelli (1995) that simultaneously estimates the parameters of the stochastic frontier and the determinants of X-inefficiency. 


\section{The Stochastic Frontier Model}

Battese and Coelli (1995) proposed a stochastic frontier model for panel data in which the inefficiencies can be expressed as specific functions of explanatory variables. The model below is a special case where only a single time period is considered (i.e., cross section). The model can be expressed as

$$
Y_{i}=x_{i} \beta+\left(V_{i}-U_{i}\right) \quad i=1, \ldots, N
$$

where $Y_{i}$ is the production of district $i ; x_{i}$ is a $k x 1$ vector of inputs; $\beta$ is a vector of unknown parameters; $V_{i}$ are random variables which are assumed to be independently and identically distributed $N\left(0, \sigma_{v}^{2}\right)$ and independent of $U_{i}$ which are non-negative random variables that account for technical inefficiencies in production; $U_{i}$ are assumed to be independently distributed as truncations at zero of the $N\left(m_{i}, \sigma_{U}^{2}\right)$ distribution. The mean inefficiency is a deterministic function of $p$ explanatory variables:

$$
m_{i}=z_{i} \delta
$$

where $\delta$ is a $p x 1$ vector of parameters to be estimated. Following Battese and Corra (1977) let $\sigma^{2}=\sigma_{V}^{2}+\sigma_{U}^{2}$ and $\gamma=\sigma_{U}^{2} /\left(\sigma_{V}^{2}+\sigma_{U}^{2}\right)$.

The inefficiencies, $U_{i}$, in equation (1) can be specified as:

$$
U_{i}=z_{i} \delta+W_{i}
$$

where $W_{i}$ is defined by the truncation of the normal distribution with 
mean zero and variance, $\sigma_{U}^{2}$. The parameters of the model $\left(\beta, \delta, \sigma^{2}\right.$, and $\gamma$ ) are estimated using the maximum likelihood estimator (MLE); the likelihood function can be found in the appendix of Battese and Coelli (1993). ${ }^{1}$

The translog production function is used, measuring output as the average district performance on standardized tests. The inputs, $x_{i}$, are functions of instructional expenditures per student $(I \$ / S)$, noninstructional expenditures per student $(N \$ / S)$, and support expenditures per student $(S P \$ / S) .^{2}$

The average inefficiency, $m_{i}$, in equation (2) is determined by, among other things, local revenues as a percent of the total school district revenue (\%Local) and local funding per household (Local\$/Household). These measures of local support are outcomes of the voting behavior (either at the polls or by the feet) of district residents.

The presence of Local\$ in both potential funding variables, $\%$ Local and Local\$/Household, complicates the interpretation of efficiency coefficients. ${ }^{3}$ So, for estimation purposes the variables are decomposed into their individual components, Local\$, Total\$, and Households in the empirical models that follow. This specification also permits one to answer two important policy questions about school efficiency. "What happens when local voters opt for a unilateral increase in their district's school funding?" And, "what happens to school efficiency if $\$ 1$ of state and federal funding is replaced with $\$ 1$ of local funds?" 4

Some studies have found that district performance is affected by other socioeconomic characteristics like the poverty rate, percent on 
subsidized school lunch, etc. Thus, the district's poverty rate is also included as a determinant of X-inefficiency. Finally, school district enrollment is likely to influence district efficiency, especially in higher grade levels where student specialization becomes more pronounced. [Chubb and Moe (1990), for instance, find a modest positive effect of school size on organizational efficiency.]

\section{Data}

Data were obtained from the Oklahoma Office of Accountability. The data are from the academic years 1990-1991. ${ }^{5}$ The output variables are the percentiles of the Iowa Test of Basic Skills (ITBS) for grades 3 (IT3) and 7 (IT7), and of the Test of Achievement and Proficiency (TAP) for grades 9 (TAP9) and 11 (TAP11) and were obtained from reports compiled by the Oklahoma Office of Accountability under the Education Indicators program. The remaining variables are from the School District Data Book published by the National Center for Education Statistics and the U.S. Department of Education.

The Oklahoma data are particularly useful in estimating an educational production function because many of the variables exhibit large variation, as can be seen in Table 1 . One of the problems in studies of this type is that district revenue can be correlated with the the wealth or income of district residents. If the children of wealthy residents are beneficiaries of unmeasured investments in human capital, then it would not be surprising to find that schools in those districts are more

efficient even if they are not. Consequently, a successful estimation 
strategy would be one that takes advantage of exogenous means of financing. In Oklahoma there is an important source of school funding that arises from way local property taxes flow to the school district. In some districts a significant portion of local property taxes flow from public utilities and services - electric power generation, natural gas service, and pipelines - which are taxed based on the location of their physical plant. This means that a school district fortunate enough to have a power generating plant (or other utility) in its confines has a high revenue base independent of the income of district residents. The exogenous variation in revenue and spending per student helps to identify the production function.

In order to take advantage of this important source of exogeneity, an instrument is created for local revenue based on the district's potential tax revenue from public utilities. ${ }^{6}$ The approach is similar in spirit to Hoxby (2001) who creates a set of simulated instruments to eliminate potential sources of endogeneity in regressors. Because the valuation of the public utility tax base is credibly exogenous to district finances, it provides a useful instrument for our purposes.

A provision in the Oklahoma Constitution sets maximum legal milages for state school districts. Potential revenues would all be a constant proportion of the valuation of public services property (VPS) and, hence, this is used in the formation of instruments for our data. The VPS is collected from Volume 2 of the Oklahoma Department of Education's 1988-1989 Annual Report (1990).

Predicted values of Local\$ and Total\$ are obtained in 'first-stage' 
regressions and used to replace potentially endogenous variables within the efficiency equations. ${ }^{7}$

\section{Results}

The MLEs are obtained for each of 4 output measures: 3rd grade, 7th grade, 9 th grade and 11 th grade test scores. The coefficient estimates and corresponding t-ratios for the frontier production functions are presented in Table 2. The lower panel of the table gives the estimates (and t-ratios) of the effects of the local support variables (along with poverty and enrollment) on X-inefficiency.

The coefficients on Local\$ are negative and significant for each grade indicating that higher proportions of spending from local sources (holding total revenue and the number of households constant) improved technical efficiency. This suggests that replacing $\$ 1$ of state or federal support with $\$ 1$ of local support will improve efficiency. The coefficients on Total\$ are positive for each grade and significantly so at the $5 \%$ level for grades 3,7 , and 9 . This supports the finding that greater proportions of funding from the local level improve efficiency.

If a district decides to unilaterally increase local support by $\$ 1$ then both Local $\$$ and Total $\$$ will increase by equivalent amounts. The analysis suggests that inefficiency will actually increase; the positive Total $\$$ effect dominates the negative Local\$ effect on inefficiency.

The other control variables in the inefficiency equation have reasonable coefficients. The poverty rate contributes to school inefficiency in each grade, indicating that it takes more dollars to achieve a given 
output in school districts with greater poverty.

The estimates of the effects of size on efficiency, which indicate that districts with more students are more efficient, are also plausible. The inefficiency decreases at a diminishing rate, reaching an optimal size in the range of 16,320 to 20,450 students. Only the Oklahoma City and Tulsa City school districts in Oklahoma have enrollments beyond this range (over 35,000 were enrolled in each district). Thus, these results suggest that larger school districts (except for the two largest) are associated with greater technical efficiency.

Although our intent is not to enter the money-matters melee, we have computed output elasticities at the mean values of $\ln (I \$ / S)$, $\ln (N \$ / S)$, and $\ln (S P \$ / S)$ based on the estimated production function in Table 3. The elasticities of test scores with respect to instructional spending are statistically positive at the $5 \%$ level for $3 \mathrm{rd}, 9 \mathrm{th}$, and 11 th grade scores. The elasticities with respect to noninstructional spending and support spending are not statistically different from zero. Based on these estimates, shifting a dollar from other to instructional spending would improve school testing performance. In addition to operating inside the production frontier (X-inefficiency), this result suggests that schools use an inappropriate mix of inputs.

To our knowledge, the results are unique in showing significant relationships between X-inefficiency and other variables. Bates (1997) and Deller and Rudnicki (1993) test for, but do not find, such relationships. Bates uses simple correlation to test for relationships between efficiency and teaching expenditure, and nonteaching expenditure, and 
socioeconomic background; the correlations are only 0.04, -0.09, and 0.04. Deller and Rudnicki use several parametric and nonparametric tests for an association between efficiency and school administrative type, school administrative spending, and school size. They find no patterns. Our detection of a relationship may be due to the use of a more efficient one-stage estimator for the frontier and the determinants of inefficiency.

\section{Conclusion}

Numerous studies of the education production function have yielded conflicting results about the effect of more resources on education outcomes (Hanushek 1996). Ample evidence exists, suggesting that some public schools do a better job than others in transforming the resources into educational outcomes. We know, citing just a few studies, that: schools or school districts matter (Deller and Rudnicki 1993), principals matter (Chubb and Moe 1990), and teachers matter (Ferguson and Ladd 1996). We contend that one of the reasons for the conflicting evidence regarding the effects of more spending per student or more teachers per student is that the average production function approach used in many studies is a misspecification. The evidence that some schools use resources more efficiently than others makes using a frontier production function compelling. In our model, we find positive but small elasticities of test scores with respect to instructional spending, and we also find significant inefficiency. Understanding the sources of

the inefficiency and figuring out ways to reduce it are as important, if 
not more important, then more resources in improving performance. Resources matter, if they are used wisely.

Although money in the form of instructional expenditures matters, there is wide variation in the efficiency with which districts use available resources to educate students. In particular we find that collecting a larger share of the district budget at the local level tends to improve efficiency. The results also indicate that merely increasing local property assessments to fund schools may not improve technical efficiency (though test scores may improve marginally) since efficiency may decline as the total revenue increases. Additionally, districts having a relatively large number of students tend to be more efficient than smaller ones.

\section{Notes}

(Coelli 1996)

${ }^{2}$ In the translog model, the natural logarithm of each variable enters in levels, their squares, and their cross products.

${ }^{3}$ For instance, if a district levies a higher property tax which increases Local\$/Household, then for \% Local to be held constant in a regression sense, Total $\$$ would have to increase proportionately.

${ }^{4}$ Interpreting the effect of changes in the number of households holding all other variables in the model constant is difficult and a thorough analysis is left for future research. The number of households in the district has several potential effects. Increasing the number of households holding funding levels constant causes local revenue per household to fall which is expected to decrease district efficiency. Another possibility is that for a given student population, having more households decreases the proportion of district households relying directly on the public school system. If districts that have relatively fewer households with children scrutinize 
district expenditures more carefully, then efficiency could increase. This effect would occur if households having children are more prone to reflexively give the 'rubber stamp' of approval to district requests. There is also the possibility of aglomeration economies associated in districts having more households.

${ }^{5}$ There are actually over 600 school districts in Oklahoma. We eliminated from our sample all that do not offer 1st through 12th grades.

${ }^{6}$ We would like to thank an anonymous referee for suggesting this.

${ }^{7}$ Instruments used include all exogenous variables in the system, $\ln (V P S)$, and VPS/Households. Both variables are statistically different from zero in the firststage regressions.

\section{References}

Bates, Jim, 1997, "Measuring Predetermined Socioeconomic 'Inputs' When assessing the Efficiency of Educational Outputs," Applied Economics, 29, 85-93.

Battese, George E. and G. S. Corra, 1977, "Estimation of a Production Frontier with Application to the Pastoral Zone of Eastern Australia," Australian Journal of Agricultural Economics, 21, pp. 169-179.

- and Tim J. Coelli, 1993, A Stochastic Frontier Production Incorporating a Model for Technical Inefficiency Effects, Working

Papers in Applied Statistics, No. 65, Department of Economics, University of New England, Amrmidale, NSW, Australia.

— and - , 1995, "A Model for Technical Inefficiency Effects in a Stochastic Frontier Production Function for Panel Data," Empirical Economics, 20, 325-332. 
Chubb, John E. and Terry M. Moe, 1990, Politics Markets $\&$ American Schools, Washington DC: Brookings Institution Press.

Coelli, Tim J., 1996, A Guide to FRONTIER 4.1: A Computer Program for Stochastic Frontier Production and Cost Estimation, Centre for Efficiency and Productivity Analysis Working Paper 96/07, Department of Economics, University of New England, Amrmidale, NSW, Australia.

Deller, Steven C. and Edward Rudnicki, 1993, "Production Efficiency in Elementary Education: The Case of Maine Public Schools," Economics of Education Review, 12, 45-57.

Ferguson, Ronald and Helen Ladd, 1996, "How and Why Money Matters: An Analysis of Alabama Schools," in Ronald Ferguson and Helen Ladd, eds., Holding Schools Accountable: Performance-Based Reform in Education, Washington DC: Brookings Institution Press.

Hanushek, Eric A., 1996, "School Resources and Student Performance," in Gary burtless, ed., Does Money Matter? The Effect of School Resources on Student Achievement and Adult Success, Washington DC: Brookings Institution Press, pp. 43-73.

Hoxby, Caroline M., 1999, "The Productivity of Schools and Other Local Public Goods Producers," Journal of Public Economics, 74 (1), 1-30.

- , 2001, "All School Finance Equalizations are not Created Equal," Quarterly Journal of Economics, 116 (4), 1189-1231.

Oklahoma State Department of Education, 1990, “1988-1989 
Annual Report, Volume 2,". 


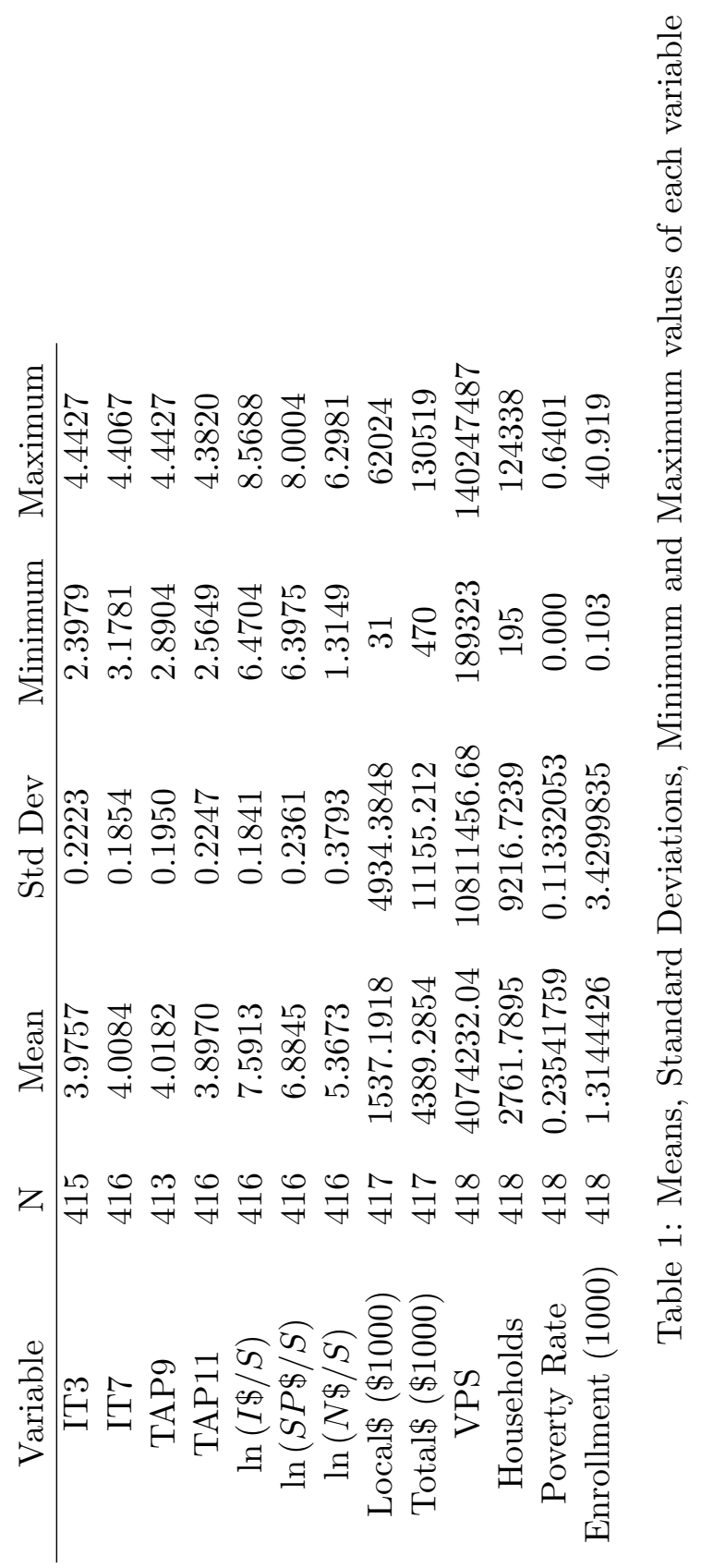




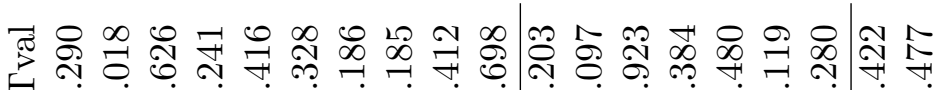
F

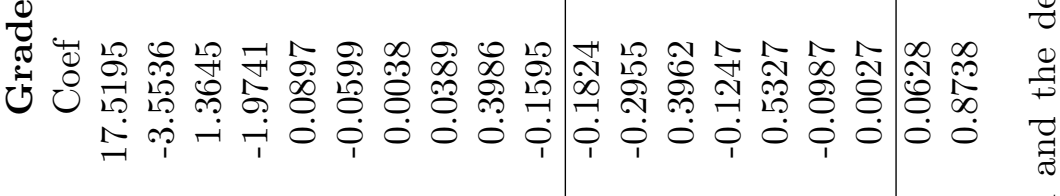

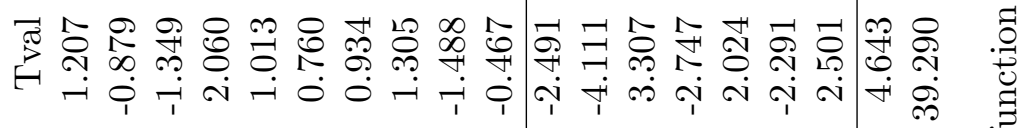

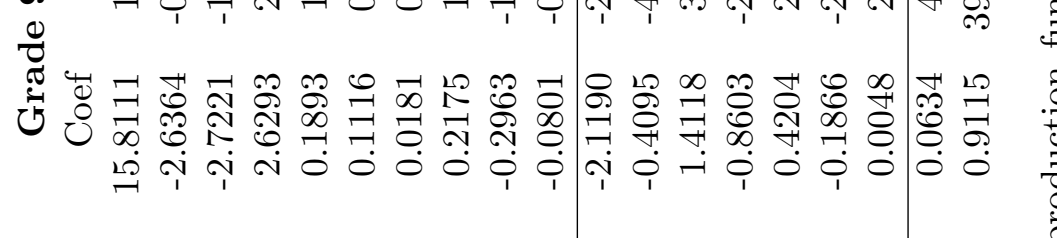
テ N $H$ O

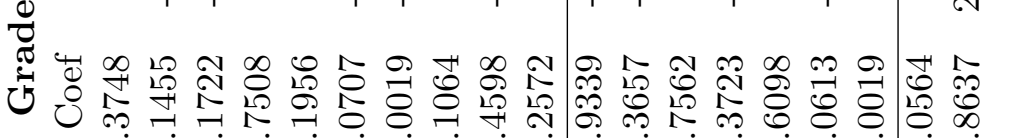


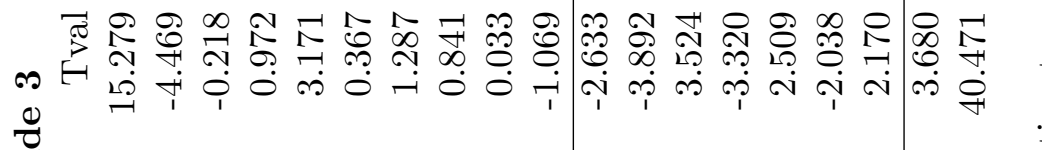

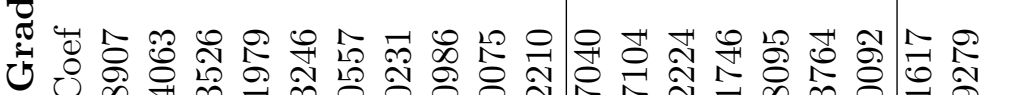
齐

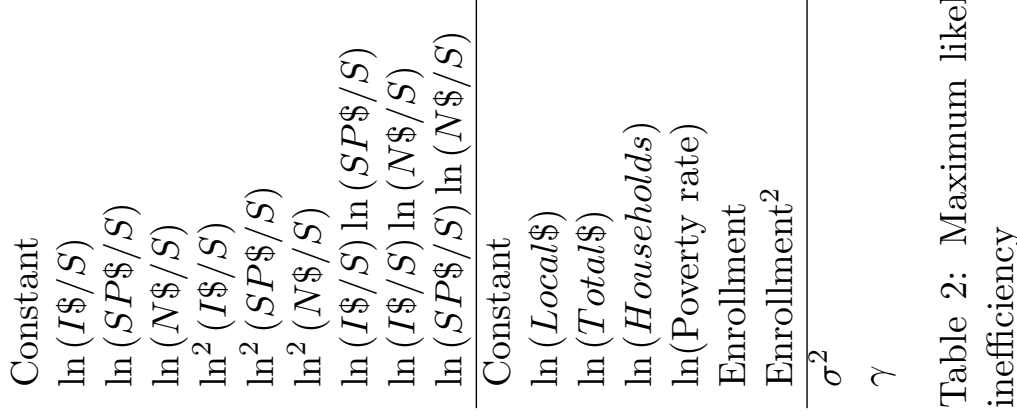




\begin{tabular}{rrrr} 
Grade 3 & Grade 7 & Grade 9 & Grade 11 \\
0.245 & 0.088 & 0.146 & 0.216 \\
$(.069)$ & $(.070)$ & $(.061)$ & $(.085)$ \\
-0.018 & 0.043 & 0.035 & -0.021 \\
$(.056)$ & $(.054)$ & $(.049)$ & $(.065)$ \\
-0.018 & 0.011 & .023 & -0.0061 \\
$(.037)$ & $(.032)$ & $(.032)$ & $(.038)$ \\
\hline
\end{tabular}

Table 3: Elasticities of test scores with respect to instructional, noninstructional, and support expenditures per student evaluated at their means. Standard errors in parentheses. 